\title{
REPENSANDO LOS PROBLEMAS DE LA ETNOGRAFÍA MULTILOCAL: \\ Intuición, emoción, reflexividad y arte
}

\author{
Javier JIMÉNEZ-ROYO \\ Universidad de Sevilla \\ javierjroyo@gmail.com
}

\begin{abstract}
RETHINKING THE PROBLEMS OF MULTI-SITED ETHNOGRAPHY: intuition, emotion, reflexivity and art
\end{abstract}

Resumen: En el presente artículo trato de exponer algunas de las problemáticas que, como otros antropólogos/as desarrollando otras etnografías que se han venido a llamar "multilocales" (Marcus, 1995), encontré cuando realizaba trabajo de campo en el sur de España y en Buenos Aires (Argentina). El funcionamiento de los sistemas de financiación del ámbito académico, los compromisos profesionales y personales, los cambios producidos entre viajes y las dificultades ya inherentes en las etnografías multilocales pusieron en peligro el proceso de producción de datos en mi propia etnografía. En línea con una puesta en valor de la etnografía en múltiples lugares, en este texto expongo cómo hice frente a algunas de sus complicaciones. Por último, propondré que la autoetnografía puede ser una vía razonable para mitigar algunas de las dificultades que impone la etnografía multilocal.

Abstract: In the present article, I try to expose some of the inconveniences that I have found when researching for a fieldwork in the south of Spain and Buenos Aires (Argentina), as it happened to many other researchers that developed the so-called multi-sited ethnographies (Marcus, 1995). The operations of the funding systems in the academic field, the professional and personal commitments, the changes that took place among different trips and the inherent adversities in the multi-sited ethnographies put in danger the data production processes of my own ethnography. Considering the value of the ethnography in different locations and communities, I explain how I bypassed some of these inconveniences. To finish, I will propose the autoethnography as a reasonable method to mitigate some of the complications naturally imposed by this multi-sited ethnography.

Palabras clave: Etnografía multilocal. Autoetnografía. Iglesia Evangélica Filadelfia. Gitanos. Buenos Aires Multi-sited ethnography. Autoethnography. Evangelical Church of Philadelphia. Gypsies, Buenos Aires 


\section{Introducción}

La intención de este artículo es hacer una defensa al uso de la etnografía multilocal ${ }^{1}$, a pesar de los lastres que podamos llevar con nosotros en nuestras maletas de viaje, encontrar en los lugares dónde aterrizamos y/o emerger al revisar las notas y grabaciones que registramos al darnos cuenta de que echamos algo en falta. Como escribió Ulf Hannerz, la "etnografía es un arte de lo posible y puede que sea mejor tener algo que no tener nada" (2003: 213. Traducido por el autor). Ciertamente, los problemas que surgen de la gestión de la temporalidad son muy acentuados en el caso de la etnografía multilocal, pero éstos y otros dilemas pueden aparecer asimismo al ajustarse al modelo canónico del trabajo de campo, que inauguraría Malinowski y sistematizaría en la introducción de Los Argonautas del Pacífico Occidental en 1922, y en sus adecuaciones posteriores. En este sentido, no deja de ser paradójico que el fundador del funcionalismo emprendiera su estudio del Kula circulando a través de distintos lugares con los isleños trobriandeses; algo que ha hecho que algunos autores (Hannerz, 2003: 202-203; Hage, 2005: 467) se pregunten por la originalidad de la propuesta de George Marcus. Por otra parte, el inexcusable compromiso holista de la antropología y los replanteamientos producidos a partir de las dos últimas décadas del s.XX en torno a las dinámicas culturales en contextos globalizados (la heterogeneidad interna de los grupos, los paulatinos desdibujamientos de los límites, la creciente importancia de la agencia y los sujetos frente a las tradiciones más estrictamente deterministas) validan el modelo de etnografía multilocal para superar tales brechas "desarrollando un conocimiento estratégicamente situado en las fracturas, los márgenes, las interconexiones entre mundos que se tocan sin saberlo" (Cruces, 2003: 167-168).

En mi caso particular, interesado en la construcción del liderazgo y la articulación de la experiencia religiosa con los modos de comprender la gitaneidad ${ }^{2}$ y situar las fronteras étnicas en una denominación evangélico-pentecostal, formada en su inmensa mayoría por gitanos calós, algunas rutas se antojan favorables a la hora de asumir algunas trabas inmanentes en la práctica de la etnografía multilocal, extrayendo el mayor partido posible a nuestros encuentros con los informantes, a la hora de organizar el material producido y de redactar nuestro el texto etnográfico.

La autoetnografía, a través del elenco de los numerosos recursos que ofrece para la creatividad a la hora de la escritura etnográfica, puede ser asimismo una alternativa, si no para eludir, al menos para atenuar las contrariedades que nos plantea la etnografía multilocal. La autoetnografía se fundamenta en un ejercicio reflexivo de hondo calado, transparente al lector, y un componente de creatividad que se aleja del perfil tradicional de los textos académicos (Feliu i Samuel-Lajeunesse, 2007; Blanco, 2012; Tilley-Lubbs, 2014; Ellis,

\footnotetext{
1 He escrito este texto a partir de mi etnografía, que he realizado dentro del marco de mi formación doctoral gracias al contrato predoctoral del V Plan Propio de Investigación que el Vicerrectorado de la Universidad de Sevilla me concedió en 2013 y a las ayudas de estancias breves en el extranjero que convoca anualmente. He de reconocer también la invitación del Dr. César Ceriani y su inestimable ayuda para que realizara mi estancia de investigación en Buenos Aires (Argentina) bajo el auspicio de la Facultad Latinoamericana de Ciencias Sociales (FLACSO sede Argentina). Asimismo, ha sido fundamental mi participación en el Proyecto de Investigación I+D (2010-2014) financiado por el Ministerio de Ciencia e Innovación titulado "La construcción política del evangelismo gitano. Iglesias, federaciones y nuevos actores políticos", del que la Doctora Manuela Cantón Delgado es responsable como Investigadora Principal.

2El uso que hago de la cursiva para enfatizar los etnónimos buscan evitar riesgos teóricos en la utilización de los mismos, tales como: la simplificación del mundo a través de su empleo, el encerrar en ellos procesos complejos y confundirlos con causas o agentes (Jiménez Sedano, 2011). En otras palabras, si no queremos terminar hablando de "etnicidad sin grupos" hemos de distinguir grupos sociales de categorías (Jenkins, 1997; Brubaker, 2002: 169). Para ello, trato de seguir los consejos de Jiménez Sedano (2011) y Díaz de Rada (2014), sobre todo a la hora de utilizar los etnónimos con la idea de señalar que cada uso remite a una concepción particular de, en este caso, los gitanos o los payos.
} 
Adams y Bochner, 2015), por lo que, de otro modo, puede operar en favor de potenciar la circunstancia de la movilidad para extraer conclusiones.

En el presente texto me propongo explorar las condiciones de posibilidad de la dimensión multilocal de mi propia etnografía y cómo pueden ser superadas aliviando los riesgos potenciales sobre los resultados. En primer lugar, expondré brevemente los motivos que me llevaron a hacer trabajo de campo al sur de España y en Buenos Aires (Argentina), es decir, a la elección del lugar concreto teniendo en cuenta los objetivos que propuse en mi proyecto de tesis doctoral. Dedicaré un segundo apartado a transitar por los obstáculos que encontré, antes de realizar mi estancia de investigación en la capital argentina. Por último, trataré de mostrar cuáles fueron mis esfuerzos por superar aquéllos inconvenientes y qué rol jugaron estos modos de proceder a la hora de reflexionar sobre mi relación con el campo y a la hora de producir datos. Para terminar, haré un repaso sobre algunas características y tipos de autoetnografía que, en su conjugación con la etnografía multilocal, pueden resultar válidos en favor de atenuar algunas dificultades o incluso otorgarles otro uso.

\section{Expectativas y transformaciones: de la comparación a la etnografía multilocal}

Desde octubre de 2013 vengo trabajando en mi tesis doctoral que versa, grosso modo, sobre la construcción de la autoridad y la articulación de la experiencia religiosa con las identidades étnicas en torno a algunas congregaciones de la Iglesia Evangélica Filadelfia (IEF en adelante). La IEF es una denominación evangélica-pentecostal compuesta en su mayoría por gitanos calós ${ }^{3}$ y que tiene en activo unos 1.500 espacios de culto en todo el territorio español, según algunos de sus líderes. Asimismo, gracias a los contactos que mi directora de tesis, la Dra. Manuela Cantón Delgado, con algunos miembros de la IEF, sabíamos que existían iglesias de la denominación en Buenos Aires (Argentina), lo que me llevó a extender mi proyecto hacia más allá del Atlántico. Pienso que no es conveniente detallar aquí algunas de las especificidades de la $\mathrm{IEF}^{4} \mathrm{o}$ del evangelismo-pentecostal más de lo necesario. Mi interés por estas cuestiones surge de mi cercanía con la gitaneidad. Esta circunstancia, a la vez, resultaría ser un recurso para la entrada al campo -a veces sin el éxito deseado-, puesto que mis dos abuelas eran gitanas, lo que en Jerez de la Frontera me convertía en un sujeto susceptible de ser reconocido como gitano, entreverao o mestizo ${ }^{5}$.

Entre mis objetivos, en un principio, planteé algo tan tradicional para la antropología social como era la comparación, en este caso, entre las IEFs de dos localidades andaluzas, Jerez de la Frontera (Cádiz) y Linares (Jáen). Pretendía conocer las razones por las cuales numerosas congregaciones de las provincias orientales de Andalucía creaban asociaciones culturales paralelas que, uniéndose a la Federación de Asociaciones Culturales Cristianas de Andalucía (FACCA), podían obtener importantes recursos económicos y ser representados por una estructura etno-política mayor ante las administraciones del Estado español y la sociedad. A diferencia de las iglesias de Andalucía oriental, las congregaciones del occidente andaluz por lo general se abstuvieron de trazar estas vinculaciones con FACCA, algo que

3Aún a riesgo de cometer una simplificación, diré que gitanos calós es el etnónimo que reciben comúnmente los gitanos/roma procedentes de la Península Ibérica. A través de la lectura de este artículo, trataré de expresar porqué pienso que es una simplificación, aunque en la nota $\mathrm{n}^{\circ} 2$ de este texto he ofrecido pistas.

4Aunque no es lo suficientemente extensa, existen algunas publicaciones acerca del pentecostalismo gitano en general y la IEF en particular. Para una aproximación a lo que algunos autores vienen llamando el Romani Revival aconsejo la consulta de la obra editada por David Thurfjell y Adrian Marsh (2014) Romani Pentecostalism: Gypsies and Charismatic Christianity. En relación al fenómeno del evangelismo entre los gitanos en la Península Ibérica, canalizado sobre todo por la IEF, las obras más extensas son Gitanos Pentecostales: una mirada antropológica a la Iglesia Filadelfia en Andalucía de Cantón-Delgado et al. (2004) y Os Aleluias: ciganos evangélicos e música de Ruy Llera Blanes (2008).

5Las dinámicas de adscripción étnicas activas en las relaciones interétnicas en Jerez son algo complejas y no es este el lugar para detallarlas. 
en sí mismo también merecía explicación. En mi proyecto inicial también tenía planeado realizar trabajo de campo en São Paulo (Brasil) y Buenos Aires.

Ya había comenzado mi trabajo de campo en Jerez de la Frontera, mi ciudad natal, y la Dra. Manuela Cantón-Delgado me había sugerido que participara en un proyecto ${ }^{6}$ que ella estaba dirigiendo. En marzo de 2014, gracias a aquella investigación, realicé un corto viaje de dos semanas a la ciudad de São Paulo y una semana a Buenos Aires para rastrear, aunque fuera de una manera tentativa, las acciones que misioneros y pastores de la IEF desarrollaban en sendas localizaciones. Resultó que en São Paulo no existía ninguna congregación de la IEF, aunque sí un interesante panorama en lo referente al liderazgo de los pastores pentecostales roma; la evangelización bautista de los ciganos calons ${ }^{7}$; y la proliferación de actores que promovían el asociacionismo roma. En la provincia de Buenos Aires sí existían dos IEFs, cada una en una localidad distinta, una en el centro mismo de la Ciudad Autónoma de Buenos Aires y otra en la localidad de San Miguel, en el conurbano bonaerense, al noreste de la capital argentina. A mi llegada a Buenos Aires, contacté con un hermano de la IEF del centro de la ciudad y con un líder político, presidente de una asociación que trabaja en favor de los roma, quien me puso en contacto con un gitano que reside en zona llamada Cruce Castelar, en la localidad de Moreno, cercana a San Miguel (provincia de Buenos Aires).

Durante aquellos días empecé a dilucidar que convenía reelaborar el plan de investigación: en São Paulo no había encontrado huella de la IEF; en la provincia de Buenos Aires había dos iglesias entre gitanos sobre los que apenas se había escrito. Con esa idea en la cabeza, exprimí mi semana en Buenos Aires todo lo que entiendo que se puede aprovechar ese tiempo en una ciudad como aquélla, para tomar un primer contacto con el campo; sin que nunca fuese suficiente. Para empezar, las dimensiones de la ciudad tan ajena entonces a mí dificultaban los movimientos. Buenos Aires, como escribió Borges (1974: 17), está formada de "ávidas calles, incómodas de turba y de ajetreo, (...) calles desganadas del barrio (...) y aquellas más afuera ajenas de árboles piadosos donde austeras casitas apenas se aventuran, abrumadas por inmortales distancias, a perderse en la honda visión del cielo y la llanura". Durante esos días me dediqué a visitar la iglesia de la zona centro de la capital, me desplacé en subte $^{8}$ a barrios a visitar a agentes implicados en el asociacionismo roma, hablaba por teléfono desde el hotel a los gitanos residentes en las localidades que conforman el área metropolitana de Buenos Aires para hablar con pastores, obreros ${ }^{9}$ y críticos con la denominación religiosa.

Dada la deriva de aquellos encuentros y conversaciones, traté de conservar el contacto con un joven fiel de la IEF al que había conocido gracias al Coordinador de América de la denominación y con un gitano anciano con el que había hablado por teléfono. Éste último había mostrado especial interés en seguir en contacto conmigo y, gracias a una conversación que mantuvimos sobre música flamenca, me ofreció su dirección de correo electrónico para que le enviase unas pistas musicales al llegar a España. Semanas después, al remitir aquellas canciones, recibí una contestación de aquel gitano: "Javi, ya he recibido unas cuantas [canciones]. Te lo agradezco y te voy a pedir que me llames «tío», porque eres un hombre de palabra y si tienes mezcla gitana, con más razón. Si te parece, claro”. No sabría explicar lo que sentí cuando leí aquella respuesta; pero algo así como una gran felicidad me inundó y noté como si alguien en una zona alejada de mi mundo compartiera repentinamente un vínculo significativo, para ellos y para mí, conmigo. Hoy en día sigo llamándolo tío, mantenemos nuestra relación vía redes sociales y no desiste en insistirme para que vuelva a Buenos Aires a visitarlo.

6 La construcción política del evangelismo gitano: iglesias, federaciones y nuevos actores políticos.

7 Traducción portuguesa del etnónimo gitanos calós.

8 Subte es el nombre que recibe en Buenos Aires la red de metro de la ciudad.

9 Para la IEF los obreros son pastores inactivos, a disposición de la denominación para ocupar el cargo de pastor en un sistema rotatorio. 
A mi vuelta de aquel viaje continúe con el trabajo de campo al sur de Andalucía. Fui a Linares, donde pretendía tomar un primer contacto con el campo, pero había saltado la noticia de que FACCA había dejado de pagar los sueldos de unos jóvenes de un taller de formación. Al llegar a la localidad jienense se hizo patente que era realmente difícil encontrar a gente que estuviera dispuesta a hablar de FACCA, ni siquiera mis interlocutores sabían con exactitud si seguía en activo. Mientras tanto, había terminado de convencerme de que la estancia de investigación que realizaría en el futuro sería en Buenos Aires. La dimensión transnacional de la IEF no se agotaba en Argentina; había pastores de la IEF yendo a predicar a otros países latinoamericanos y había oído hablar de misioneros de la denominación tratando de erigir locales de culto en Chile. Sin embargo, la existencia de espacios donde poder acceder a los cultos fue motivo suficiente para elegir Buenos Aires dentro de las posibilidades, ésta me otorgaba la oportunidad de establecerme en un lugar durante un tiempo considerablemente continuado, a diferencia de las opciones que me brindaba el trabajo de campo con misioneros y predicadores, que presumiblemente me exigirían mayor movilidad en tiempos más reducidos.

Lo ocurrido en torno a FACCA cambiaba las circunstancias y, por otra parte, había elegido uno de los vínculos transnacionales posibles de la IEF. Había que reorganizar el plan de investigación. Resolví entonces que más que encarar la investigación, al menos en Andalucía, como una comparación en el sentido clásico que le ha dado la antropología, había que asumirla como una etnografía multilocal en su sentido más estricto, teniendo en cuenta además mi interés en volver a visitar las IEFs en Buenos Aires. Por ello asumí la comparación de un modo subyacente, tal y como la comprende Marcus en torno a la etnografía multilocal (1995: 115). Tendría presencia en el trabajo que quería desarrollar pero ahora de un modo fragmentado, emergente, y decidí centrarme en rastrear los flujos de los conflictos de liderazgo religioso, étnico y político y de la asignación de la gitaneidad entre grupos, así como la constitución de una sensibilidad compartida entre los fieles de la IEF a través de las prácticas rituales.

\section{La ausencia de circunscripciones: el riesgo de comprometer la etnografía}

Cuando determiné asumir mi investigación como una etnografía multilocal, germinaron casi simultáneamente una serie de dilemas de no fácil solución. Por un lado, algunos tenían que ver con mi reticencia y desgana hacia el manejo de redes sociales, algo que me convertía progresivamente en una rareza sobre todo para mis conocidos, pero que había que considerar en cuanto medios que los gitanos utilizaban cotidianamente para relacionarse entre ellos, también a escala transnacional; por otra parte, se me habrían de plantear restricciones en relación a mis obligaciones como contratado predoctoral del Departamento de Antropología Social de la Universidad de Sevilla y el sistema de financiación de estancias de investigación destinado a este perfil laboral; y por último, aunque esto era del todo inesperado, debía hacer frente a las drásticas alteraciones que se habían producido en torno a la IEF de Buenos Aires durante el intervalo de tiempo que transcurrió entre mi primera visita, en marzo de 2014, y la segunda, a principios de agosto de 2015.

Cada vez encontraba con mayor frecuencia a fieles de la IEF que me preguntaban por mi perfil de facebook. Al principio de la investigación decía sin vacilaciones que no poseía una cuenta en dicha red social, pero cada vez se hacía más evidente que era un espacio que atravesaba el campo social en el que me había implicado. La insistencia de mis interlocutores hizo que me decantara por inaugurar una cuenta en facebook, aunque nunca lo tomé como un medio para hacer ciberetnografía o etnografía virtual, sino para conservar los contactos, sobre todo los más lejanos: los gitanos que conocí en mi primera visita a Buenos Aires y los activistas roma con los que me había encontrado en Brasil y Argentina. Frecuentemente recibía como regalo vídeos de predicadores afamados en América Latina, noticias de accio- 
nes de discriminación institucional hacia los ciganos calons que vivían en campamentos en diversas áreas urbanas del Estado de São Paulo y las reprimendas de aquel gitano de Cruce Castelar por el lapso de tiempo que se sucedía entre nuestras comunicaciones. "Javier, estás perdío, ya no te acuerdas de nosotros", leía con angustia cada pocos meses en el chat que ofrece la red social. Estos reproches se han repetido hasta la actualidad, e invitan a aceptar que los límites entre lo personal y lo profesional son muchos más difusos de lo que a veces pudiéramos desear. En lo que a mí conciernen, estas amonestaciones me hacen cuestionarme si debí haber prestado atención a las redes sociales de forma más sistemática e intensa con fines académicos. Me había rendido a estar activo en un espacio ajeno hasta entonces para mí, pero ineludible para comunicarme con muchas de las personas que conocía. De esta forma, procuraba integrarme en sus dinámicas relacionales tal y como lo hacían ellos. Sentía que podía mantener las relaciones con mis amistades intactas sin el esfuerzo que me suponía estar activo en facebook, pero no estaba tan seguro de lo mismo de cara a mis colaboradores en el campo.

En marzo de 2015, un año después de mi visita a Brasil y Argentina, me encontraba gestionando la estancia de investigación que, como contratado pre-doctoral del Departamento de Antropología Social de la Universidad de Sevilla, me ofrecía el Vicerrectorado de Investigación. Las obligaciones adjuntas a la figura de lo que en la práctica era un becario implicaban algunas, no muchas, horas de docencia, que yo vivía con ansiedad por la novedad que suponía aquella labor para mí y por las inseguridades que me provocaban. Necesitaba demasiadas horas, pensaba yo, para preparar una sola hora de clase. Las limitaciones de la financiación y los créditos de docencia asignados influyeron para que preparara mi nueva estancia en Buenos Aires entre los meses de agosto y noviembre, entre el invierno y la primavera bonaerense. Nunca me parecieron suficiente tres meses, tampoco me lo parecen hoy, pero no me quedaba otra opción si quería abarcar todas las responsabilidades a las que mi contrato me comprometía. Por suerte, era el tiempo mínimo susceptible de ser reconocido académicamente como "estancia de investigación", un mérito intercambiable como capital para el futuro profesional. La etnografía, en su naturaleza como procedimiento de producción, organización y distribución del conocimiento sobre la condición humana, tiene la suficiente entidad en la vida de los investigadores como para que entre en contradicción con facilidad con el trabajo académico ${ }^{10}$. Y el problema fundamental que encuentro en la etnografía multilocal, el que más constriñó mi investigación y donde además se sitúa uno de los centros de la diana de las críticas, es el de la temporalidad. Los escasos tiempos que se atribuyen a las etnografías multilocales responden generalmente a tres problemas: 1) el aprendizaje del idioma local, 2) la validación de los datos que influye, a su vez, en las técnicas de producción de los datos mismos y 3) la imposibilidad de establecer relaciones profundas con los informantes en trabajos de campo de carácter multilocal (Hannerz, 2003: 209 y ss.). De este modo, a través de las redes insertas en el sistema de autoridad de la IEF, conseguí acceso al campo; a través de contactos académicos tuve la oportunidad de conversar con un activista político roma, quien posteriormente me abrió la puerta de otras iglesias gitanas activas en la capital y me dio el contacto de gitanos críticos con la iglesia. Con algunos de ellos, mantengo hoy en día vínculos a través de las redes sociales donde, en un comienzo, me resistía a participar.

Aunque indudablemente arrastra serios retos, una de las potencialidades de la etnografía multilocal es que te permite un periodo de reflexión y planificación, más o menos prolongado, entre las idas y venidas de un lugar a otro (Hannerz, 2003: 213). Durante más de un año mantenía contacto con algunas de las personas que había conocido en el campo y comencé

10 Algunos autores han reflexionado sobre las limitaciones personales y profesionales que pueden acentuarse al realizar trabajo de campo en diversas localizaciones (Amit, 2000: 9; Strauss, 2000: 166; Hannerz, 2003: 212213; Hage, 2005: 465). 
a planificar escrupulosamente los objetivos a alcanzar durante mi estancia en Buenos Aires tres meses antes de mi partida -requisito asimismo obligado para la obtención de financiación. Sin embargo, y aunque uno tenga presente el cambio continuo de las cosas, sobre todo en su realidad más inmediata, a mí me ocurrió como a la señora de Jauregui del cuento de $L a$ Señora Mayor de Borges (2014: 386), quien "quizá no sospechaba que Buenos Aires había ido cambiando y creciendo". Semanas antes de embarcar en el vuelo que me llevaría a la orilla sur del Río de la Plata, me llegaron noticias que hacían renacer con fuerza muchos de los problemas enumerados arriba. Por un lado, mi preciado interlocutor, prometedor líder de la IEF, había abandonado la congregación hacía meses para adherirse a otra denominación, que tenía un local dedicado al culto entre gitanos del barrio y que se encontraba a una cuadra $^{11}$ del templo de la IEF. Por otra parte, el líder político, quien un año antes me había brindado el contacto de aquel gitano de la localidad de Moreno, había entablado un conflicto con éste. En aquellos momentos no sabía con certeza que me esperaría a mi llegada, pero entretanto me afanaba en pensar cuánto de deterioradas podían verse mis relaciones a partir de las disputas provocadas: ¿provocaría una posible conversación con el líder político el malestar del residente gitano del conurbano bonaerense, o cierta desazón del primero si me citaba con el segundo? ¿levantaría sospechas entre los conversos de la IEF si decidía visitar la nueva iglesia evangélica gitana del barrio? $\mathrm{O}$ a la inversa ¿perdería mi colaborador, un año antes hermano de la IEF, la confianza en mí si me dedicaba a asistir únicamente a los cultos de la IEF? En mi cabeza todo perdía el orden provisionalmente establecido. Había que decidir. Podían estar entrando en juego las relaciones que mantenía con algunos de mis interlocutores en Argentina, y si el periodo de estancia iba a ser breve, ahora parecía contraerse cada vez más.

En la siguiente sección expondré cómo finalmente traté de frenar, a veces gracias a casualidades, los problemas que suponían para mí el desarrollo de trabajo de campo en Buenos Aires. Las determinaciones que tomé y una posterior y creciente atención a mis propias emociones trajeron sucesivas revelaciones dignas de considerar en el análisis. Por último, propondré algunos recursos que pueden auxiliarnos a la hora de hacer frente a las posibles obstrucciones de la etnografía multilocal.

\section{Admitir las inherencias. La instrumentalización de los «problemas»}

A pesar de los contratiempos sobrevenidos las semanas anteriores a mi viaje, decidí, quizá imprudentemente, tomar las decisiones sobre el campo mismo, recurriendo a mi propia intuición, aquella "síntesis de toda la experiencia y de todos los saberes del investigador, incluidos sus rasgos temperamentales y emocionales" (Jociles Rubio, 2005: 2). Escribe Stoller (1997: 91. Traducido por el autor) que "la clave para investigar en espacios transnacionales complejos pienso que recae menos en los métodos, los equipos multidisciplinares y los marcos teóricos - aunque que son importantes sin duda-, que en la flexibilidad de la imaginación". Para mi sorpresa, las relaciones que había procurado mantener durante 16 meses no se vieron socavadas ante mi determinación de visitar los dos cultos gitanos del barrio del centro de Buenos Aires, ni de visitar al líder político roma y al gitano de Cruce Castelar. Creo, en ese sentido, que el uso de las redes sociales para tratar de conservar en el tiempo dichas relaciones, surtieron efecto. Unos y otros me facilitaban nuevos encuentros y nuevas situaciones. Además, el Coordinador de la IEF en América me había facilitado el contacto del pastor de la IEF de la capital, y éste me invitó a asistir al culto a mi antojo y me atendió siempre que lo necesité. Todo ello habla del funcionamiento de la autoridad en la estructura de la denominación gitana, de las vinculaciones entre el asociacionismo y el evangelismo, etc. El uso de los contactos intermedios en el desarrollo de la etnografía mul-

11En Argentina una cuadra mide aproximadamente 100 metros y es la distancia que separa la esquina de una calle con la esquina sucesiva. 
tilocal puede jugar a favor del hallazgo de conexiones (Hannerz, 2003: 209).

Asimismo, la escisión en la IEF y la fundación de la nueva iglesia se había producido en el espacio de tiempo que se había sucedido entre mis dos visitas a Buenos Aires. Muchas veces me había interpelado a mí mismo convenciéndome, como si la circunstancia pudiera ser reparada, de que lo mejor hubiera sido estar presente en el campo cuando ocurrió aquella situación, pero este era un problema que la etnografía multilocal compartía con las etnografías que se centraban en un solo territorio y que se desarrollaban con una disponibilidad de tiempo mayor. Al fin y al cabo las unidades temporales que buscamos abarcar en nuestras etnografías superan generalmente nuestras estancias en el campo mismo y, en palabras de García García: "es de sentido común admitir que observamos menos de los que nos cuentan, y que nuestra emblemática observación participante no deja de estar plagadas de discursos (...) La estrategia de la observación es discursiva" (García García, 2000: 77).

Pero tenía que sacarle el máximo partido a mi estancia y tampoco dejaban de sucederse nuevos acontecimientos: mi colaborador más sólido en el centro de Buenos Aires volvió a congregarse en la IEF a los pocos días de mi llegada a Argentina y el Coordinador de la IEF de América voló a Buenos Aires en septiembre para visitar las iglesias de la denominación. Con el segundo pude visitar la iglesia del conurbano bonaerense; conocer los proyectos y las expectativas a corto plazo de la IEF en Argentina; verificar que las congregaciones locales mantenían intercambios con frecuencia, al menos en presencia de una autoridad tal como el Coordinador de América, a pesar de reunir en ellas a gitanos residentes en dos áreas diferentes y que se percibían a sí mismos como diferentes entre ellos, gitanos más auténticos en definitiva, y, de esta forma, empecé a comprobar que la denominación era el principal canal para establecer relaciones entre individuos que habían restringido sus relaciones en el seno de su grupo o de su red de familiares. Además, la última tarde que el Coordinador pasó en la capital absolvió públicamente al antiguo pastor de la IEF, sancionado hasta ese día sin poder predicar. Pensé que el cambio de pastor se trataba de una rotación en el cargo, puesto que el sistema de liderazgo en la IEF en España está sometido a alternancia, pero esta circunstancia lo desmentía. Los pastores de la IEF en la provincia de Buenos Aires no rotaban entre las iglesias, dadas las reticencias por las relaciones limitadas que sostenían entre los distintos grupos, y rara vez se turnaban los obreros en el puesto de pastor de la IEF de la misma iglesia.

Encontré, por otra parte, que el siempre insuficiente tiempo que tenemos para desarrollar nuestro trabajo de campo en diversos lugares puede, en algunas situaciones, acelerar algunas situaciones. Nuestros colaboradores suelen conocer, o al menos los míos lo sabían, que tenemos un billete de regreso no muy lejano en el tiempo a nuestros hogares, y esta ecuación es inseparable de lo que nos cuentan -o de lo que deciden no contarnos. El día en que me despedía de uno de mis colaboradores más estrechos, mientras hablábamos tranquilamente en la terraza de un bar, se apresuró a sincerarme sus inquietudes más recónditas, aquellas que parecían emitir una voz de auxilio hacia mí, un ruego a mi comprensión. Este era un joven atrapado en las contradicciones comprendidas entre los imperativos de su denominación religiosa y los límites de las relaciones interétnicas, entre el 'sistema de Dios' y el 'mundo gitano'. Por otra parte, la última semana que pasé en Buenos Aires, durante una de mis visitas a uno de las congregaciones gitanas de la capital, el pastor se acercó a mi durante la celebración del culto y dijo públicamente: 'Dios está más cerca de lo que tú te crees, no lo busques en el pueblo, búscalo en tu corazón'. Con aquellas palabras estaba abriéndome las puertas de su fe e intentando que aquella corta historia tuviese un final feliz de su propia mano. Con aquellas palabras me estaba ofreciendo lo mejor que él podía darme antes de que fuese demasiado tarde para mí; a la vez que enseñaba a la iglesia en qué consiste una buena administración de la congregación y una adecuada aplicación de la palabra de Dios antes de que fuese demasiado tarde para él.

Las "soluciones" que yo encontré -independientemente de la eficacia del resultado- son 
difícilmente trasladables a otras investigaciones. Las texturas que adquiere la realidad desbordan cualquier intento de aplicar inapelablemente muchas de las técnicas de investigación que aparecen en los manuales de etnografía. Por ello, si bien la entrevista resulta la técnica habitualmente privilegiada en algunas de las investigaciones multilocales dadas las limitaciones temporales (Hannerz, 2003: 211), yo podía, al menos, estar presente en el desarrollo de los cultos evangélicos. Por otra parte, me incliné por conversaciones informales más que entrevistas estructuradas, no obstante en algunas ocasiones utilicé instrumentos para el registro de información, como la grabadora o un cuaderno de notas. La entrevista, dentro del elenco de técnicas etnográficas que todos tenemos en mente, escribe Favret-Saada, es uno de los medios más pobres de comunicación humana; razón por la cual ella concede estatuto de prioridad a la comunicación no-intencional (2005: 161). Para acercarnos al fondo de la experiencia humana, la autora propone que vivamos lo que los sujetos implicados viven dejándonos afectar por las dinámicas que tratamos de entender (2005). Durante mi propio trabajo de campo, como expliqué anteriormente, guardaba sobre la manga un recurso que exploté en innumerables ocasiones. Decía, para ganarme la confianza de mis interlocutores, que mis abuelas eran gitanas, dejando que mis oyentes me devolvieran alguna consideración sobre mi grado de pertenencia étnica ${ }^{12}$. La eficacia de esta declaración estaba determinada por el contexto, y en Buenos Aires me trataban por lo general como alguien diferente a ellos, como a un payo ${ }^{13}$. Yo estaba preparado para ello, también me había pasado con anterioridad en Linares. Sin embargo, un episodio me hizo darme cuenta de hasta qué punto estaba enredado en las lógicas de las adscripciones étnicas. Una tarde tomaba café con uno de los gitanos residentes en el centro de Buenos Aires, con su abuelo y con un amigo suyo. Los dos jóvenes estaban muy comprometidos con la fe pentecostal y aquella tarde discutían sobre algunas cuestiones teológicas. A los pocos minutos sonó el teléfono móvil del anciano y contestó diciendo: 'Estoy aquí tomando un café con tu hijo, que está con dos jambos $^{14}$ '. Aún pienso en ello y siento cierta frustración, aunque mitigada por el paso del tiempo. En casa nos habían insistido en el orgullo que implicaba ser gitano. Fue al cabo del tiempo, momento en el que casi lograba dar de lado a la desilusión de no sentirme reconocido, cuando me di cuenta de que aquél episodio reflejaba hasta qué punto estaba inundado de la lógica según la cual los gitanos se distinguían entre ellos. Las palabras de Teresa San Román sobre las consideraciones mutuas entre gitanos de distintos patrigrupos ilustran esta dinámica: "Cada uno era pelúo para alguien y se defendía tildando a ese alguien de apayao" (1997: 210. Cursivas en el original). Solo entonces logré aproximarme a los reveses que sentían algunos trabajadores de la Fundación Secretariado Gitano (FSG) en Linares cuando, muchos meses después, me explicaron que el resto de gitanos los tildaba de apayaos por haber cursado estudios superiores. Moverme a través de localizaciones distintas resultó fundamental para entender algo que, de haberme quedado en Jerez de la Frontera, quizá no hubiera alcanzado a comprender. Pero hacía falta también el reconocimiento de mis propios sentimientos para vislumbrar la magnitud de la emoción humana implicada en las imputaciones de las identidades.

Después de todo esto puede permanecer en el lector el convencimiento de que el principal problema que tenemos como antropólogos haciendo etnografía multilocal es el de

12 Encuentro que la incomodidad que sentía ante la posibilidad de declararme a mí mismo gitano ante la atención de mis colaboradores, la comparte por ejemplo Laura Zapata, quien recuerda la perturbación que sentía al reconocerse a sí misma como india, lo que le llevó, como a mí, a recurrir a la descripción de los vínculos familiares que daban cuenta de la pertenencia parcial a los grupos (2014: 185). Ella encontró asimismo el potencial de las ideas de Favret-Saada: "es preciso (...) dejarse afectar por la palabra nativa, abriendo la posibilidad de la desestabilización del discurso y teoría del/a antropólogo/a, descolonizando el poder referencial (orientalizador) cifrado en el texto etnográfico (Ibid:: 220).

13 Payo es uno de los etnónimos que los gitanos calós utilizan para referirse a los no-gitanos.

14 Jambo, al igual que payo, es un etnónimo para referirse a los no-gitanos. 
establecer hondas relaciones con nuestros colaboradores e integrarnos en el grupo por el que nos interesamos en favor de la validez de los datos. Y no es que no sea cierto, es un límite al que nos obliga a enfrentarnos los que intentamos hacer etnografía multilocal. Pero también conviene recordar que siempre interrumpimos en algún grado el curso de las vidas de nuestros colaboradores. Al hacerlo, estamos evidenciando la impostergable necesidad de renuncia de la búsqueda de explicaciones generalizables (Abèlés y Badaró, 2015: 22). Por estas razones, pienso que se pueden tomar vías alternativas que reconociendo las limitaciones de la etnografía multilocal puedan extraer un mayor rendimiento ellas.

Se me antoja que algunas de las propuestas de la autoetnografía pueden, si no suprimir completamente los obstáculos, al menos retenerlos de un modo intelectualmente beneficioso. Para ello, eso sí, hemos de dar un paso más dando de lado a los criterios de las epistemologías de corte racionalista para inmiscuirnos en el mundo de los significados o de las emociones de una forma más reflexiva y creativa. Escribe Stoller que la antropología quizá sea, de entre todas las ciencias humanas, la más personal y que, por ello, la influencia de nuestro yo-personal sobre nuestro yo-profesional sea difícil aquietar (2007: 179). A partir del reconocimiento de nuestra implicación vital en los mundos que observamos con las lentes de un profesional, quizá algunas formas de orientar la autoetnografía puedan servirnos para socavar o, de otro modo, convertir en potencialidades algunos inconvenientes que arrastran la movilidad o la duración de nuestras estancias.

\section{Incorporar los problemas. La autoetnografía como alternativa}

Aunque la autoetnografía no nace para resolver los posibles problemas de la etnografía multilocal, pienso que los condicionantes fundamentales de la práctica autoetnográfica, un ejercicio de reflexividad profundo y permanente y una importante dosis de creatividad en el relato, pueden ser un buen punto de partida para transformarlos. Me detendré en algunas de las carcaterísticas fundamentales de la autoetnografía para posteriormente argumentar su utilidad. "La autoetnografía es un género autobiográfico de escritura e investigación que despliega múltiples estratos de la consciencia conectando lo individual a lo social" (Ellis y Bochner, 2000: 739. Traducido por el autor). Si la experiencia del propio investigador toma protagonismo en favor del descubrimiento de las culturas que estudiamos (Ibid.: 740), tomar en consideración las condiciones a las que sometemos nuestras etnografías multilocales y las implicaciones personales que aparejan, pueden ayudarnos a reflexionar sobre la producción de conocimiento en dichos contextos. No se trata, como puede quizá entenderse, de un alegato en favor de cierta negligencia a la hora de hacer trabajo de campo mismo; se trataría, más bien, de dejar translucir las restricciones, sus consecuencias y la operación que implican en nuestros conocimientos, sentimientos, pensamientos y el proceso mismo de producción de datos, equilibrando la presencia del investigador en el texto con respecto a nuestros colaboradores, o a veces representando el papel protagónico. Todo ello a través de la escritura de textos estéticamente estimulante, con la que además se busca llegar abarcar a un público más amplio que el que tradicionalmente lee nuestros trabajos. De esta manera, las pretensiones explicativas se atenúan, "enfatizando el viaje sobre el destino" (Ibid.: 744. Traducido por el autor), la validez y la generalización sufren desplazamientos hacia los dominios del lector. La validez recae en la verosimilitud, plausibilidad y credibilidad que la narrativa tiene para éste y la generalización depende de su verificación a partir del contraste de lo que se cuenta con su propia experiencia o con las de otras personas que conoce, sin olvidar que el relato fotografía a las personas como individuos con biografías originales a la vez que vinculados entre ellos (Ibid: 751). Creo que en la búsqueda de flujos o conexiones transnacionales, la autoetnografía puede ser un reto para medir el alcance de ciertas instituciones en la vida de los individuos sobre el binomio individual-cultural. De hecho, Marcus ya consideró las historias de vida como técnica vigente en la práctica etnográfica multilocal 
(1995: 121), una técnica que invita a recorrer el camino que va desde las narraciones autobiográficas hacia el nivel de la sociabilidad.

Pero este argumento no neutraliza el problema de la temporalización del trabajo de campo y es quizá ese mismo problema el que hemos de poner en valor en nuestras (auto)etnografías multilocales. Vamos a tratar de darles la importancia que merece. Existen tipos reconocidos dentro del elenco de textos reconocidos como autoetnografía, pero mi objetivo no es enumerarlos, sino sugerir la vigencia de algunos de ellos o de sus propuestas para afrontar los retos del despliegue de la etnografía en diversos espacios. Me valdré de ejemplos que tienen alguna relación con mi propio trabajo de campo para tratar de mostrar su utilidad, aunque éstos están faltos de todo mérito artístico, requisito más que deseable en la realización de autoetnografía.

Un recurso estimulante puede ser el empleo de "narrativas personales evocativas", donde prima la dimensión personal del antropólogo durante la realización del trabajo de campo sobre la de los nativos (Feliu i Samuel-Lajeunesse, 2007: 268). En este caso, el hecho del viaje cobraría una importancia fundamental, haciendo énfasis en sus etapas, las ansiedades que generan, las preguntas que se nos plantean de antemano, mientras que en paralelo se puede contrastar cómo los gitanos o los pastores gitanos evangélicos de uno y otro lado del Atlántico nos reciben, qué rol nos atribuyen, cómo toman parte en el entorno donde nos encontramos, cómo nos descubren lo que ellos interpretan de nuestro interés mientras que se ponen de relieve las diferencias de las categorías del sentido común y las categorías de análisis. En mi propias circunstancias, podría utilizarla, además, para conocer cómo negocian sobre mi propia pertenencia étnica en lugares diversos. Al centrarse sobre todo en el investigador, la movilidad sería una circunstancia que potenciar más que un problema al que buscar una solución, subrayando un progresivo desvelamiento del oculto contexto que nunca termina de producirse.

Similar al anterior aunque otorgando mayor importancia a los nativos, las "etnografías narrativas" nos permiten articular nuestra experiencia con la descripción y el análisis (Ellis, Adams y Bochner, 2015: 256). Los encuentros, que en la etnografía multilocal prometen fugacidad, habría que tomarlos asumiendo su naturaleza, y reflexionar sobre el rol que juega esa condición en nuestras confluencias con nuestros interlocutores. En el caso de proceder del mismo lugar de origen que las personas que estudiamos, sea real o imaginado, las consideraciones hacia aquella región, nación, Estado, etc. y la negociación entre nosotros y ellos pueden intensificarse y tomar protagonismo en el texto etnográfico. En mi propio trabajo de campo, a pocos días de encontrarme con uno de mis contactos, éste me pidió insistentemente que le explicara a la persona que lo acompañaba las dificultades económicas por las que estaba pasando el país para, sin ocultarlo, convencerlo de que lo mejor era permanecer en Buenos Aires. A la vez, algunas de las personas que conocí en la capital argentina me insinuaba que debía volver pronto allí, donde consideraban que existían más oportunidades profesionales que en España.

Volviendo a la dimensión inseparablemente personal que tiene en nosotros la etnografía, podemos escribir ésta en su modo más reflexivo, aunque atendiendo sobre todo a la transformación que la etnografía opera en el investigador. El desplazamiento entre lugares puede ser pensado en forma de "etnografía reflexiva" (Ellis, Adams y Bochner, 2015: 257), sobre todo si parte del trabajo de campo lo hacemos en nuestro entorno más cercano y nos detenemos en la acentuación del cambio cuando nos desplazamos. Anteriormente describí una situación, dentro de otras muchas, en el que una persona me imputaba mi propia gitaneidad durante una conversación como un tercero, era ciertamente difícil que esto ocurriera cuando desarrollaba mi trabajo de campo en la localidad donde nací. Lejos de lo que yo pensaba, no terminaba de pensar la gitaneidad como una mera construcción simbólica, como creía hasta entonces; tuve que marcharme a Buenos Aires y enfrentarme a dicha situación para darme cuenta de la profundidad emocional del calado de la identidad, por mucho que me 
hubiesen contado los textos académicos. En este sentido, la transformación operó no solo a nivel práctico, sino sobre mis convencimientos teórico y epistemológicos. La eficacia de dicha transformación es en este punto independiente de la temporalidad, dado que emerge de un hecho casual.

La autoetnografía se produce de un diálogo entre el proceso de investigación, la cultura que pretende estudiarse y el propio investigador; queda a la elección del último dónde hacer mayor énfasis (Ellis y Bochner, 2000: 740). Creo que para responder a nuestra preocupación sobre los escollos que pueden presentarnos la práctica de la etnografía multilocal, lo más sencillo y práctico es otorgarle mayor importancia al proceso de construcción del conocimiento, pero porqué no pensar que quedan rutas por explorar en favor de buscar mayor equilibrio entre los tres ejes. De la misma forma que existen las novelas románticas, policiacas o de aventuras, también existen las novelas de viajes. Lo fundamental creo, es tomar en serio a Ellis, Adams y Bochner (2015) cuando escriben que "los autoetnógrafos asumen un punto de vista diferente hacia un objeto de la ciencia social. En palabras de Rorty, estos diferentes puntos de vista no son "cuestiones para ser resultas", en cambio, son "diferencias para ser vividas" (citado en Ellis, Adams y Bochner, 2015: 264). Esas diferencias, en nuestro caso particular, como antropólogos trabajando en múltiples lugares, deberán entonces ser experimentadas por el lector con toda la intensidad de nuestros movimientos.

\section{Bibliografía}

Abèlés, M. y Badaró, M. (2015). Los encantos del poder. Desafíos de la antropología política. Buenos Aires, Argentina: Siglo Veintiuno.

Amit, V. (2000). Introduction: constructing the field. En V. Amit (Ed.), Constructing the Field: Ethnographic Fieldwork in the Contemporary World: 1-18. Nueva York, Estados Unidos: Routledge.

Borges, J. L. (1974). Obras Completas (1923-1972). Buenos Aires, Argentina: Emecé Editores.

Borges, J. L. (2014). Cuento Completos. Barcelona, España: Debolsillo.

Brubaker, Rogers. (2002). Ethnicity without groups, European Journal of Sociology, 43(1), 63-189. doi:10.1017/S0003975602001066

Cantón-Delgado, M. et al. (2004). Gitanos Pentecostales: una mirada antropológica a la iglesia Filadelfia en Andalucía. Sevilla, España: Signatura.

Cruces, F. (2003). Etnografías sin final feliz. Sobre las condiciones de posibilidad del trabajo de campo en contextos globalizados. Revista de Dialectología y Tradiciones Populares, 58(2), 161-178. doi: http://dx.doi.org/10.3989/rdtp.2003.v58.i2.154

Díaz de Rada, Á. (2014). En el nombre del pueblo. Una reflexión para la crítica de los etnónimos en la escritura antropológica. En M. Cátedra y M. J. Devillard (Eds.), Saberes Culturales. Homenaje a José Luis García García: 181-199. Barcelona, España: Bellaterra.

Ellis, C. y Bochner, A. P. (2000). Autoethnography, personal narrative, reflexivity. En N. K. Denzin e Y. S. Lincoln (Eds.), Handbook of Qualitative Research: 733-768. Thousand Oaks, CA: Sage.

Ellis, Carolyn; Adams, Tony E. y Bochner, Arthur: 2015. Autoetnografía: un panorama. Astrolabio, $14,249-273$.

Favret-Saada, J. (2005). Ser Afetado. Cuadernos de Campo, 13, 155-16.

Feliu i Samuel-Lajeunesse, J. (2007). Nuevas formas literarias para las ciencias sociales: el caso de la autoetnografía. Athenea Digital: revista de pensamiento e investigación social, 12, 262-271.

García García, José Luis (2000). Informar y Narrar. El análisis de los discursos en las investigaciones de campo. Revista de Antropología Social, 9, 75-104.

Hage, G. (2005). A not so multi-sited ethnography of a not so imagined community. Anthropological Theory, 5(4), 463-475. doi: 10.1177/1463499605059232

Hannerz, U. (2003). Being there... and there... and there! Reflections on Multi-Site Ethnography. Ethnography, 4(2), 201-216. doi: 10.1177/14661381030042003

Jenkins, Richard (1997). Rethinking ethnicity: arguments and explorations. Londres, Reino Unido: Sage. 
Jiménez Sedano, L. (2011). Más allá de los etnónimos: ideas para escapar del secuestro intelectual de estas categorías emic en antropología de la educación. Actas del XII Congreso de la FAAEE: 2689-2698. León: Universidad de León. Recuperado de http://www.antropologiacastillayleon.org/congreso/pdf/actas\%20congreso\%202011.pdf

Jociles Rubio, M. I. (2005). El análisis del discurso: de cómo utilizar desde la antropología social la propuesta analítica de Jesús Ibáñez. Ava. Revista de Antropología, 7, 1-25.

Llera Blanes, R. (2008). Os Aleluias: ciganos evangélicos e música. Lisboa, Portugal: Instituto de Ciências Sociais.

Marcus, G. E. (2001). Etnografía en/del sistema mundo. El surgimiento de la etnografía multilocal. Alteridades, 11(22), 111-127.

Meyer, Birgit (2009). Introduction: From Imagined Communities to Aesthetic Formations: Religious Mediations, Sensational Forms, and Styles of Binfing. En B. Meyer (Ed.), Aesthetic Formations: Media, Religions, and the Senses: 1-28. New York, Estados Unidos: Palgrave Macmillan.

San Román, T. (1997). La diferencia inquietante: viejas y nuevas estrategias culturales de los gitanos. Madrid, España: Siglo Veintiuno.

Stoller: (1997). Globalizing Method: The Problems of Doing Ethnography in Transnational Spaces. Anthropology and Humanism, 22(1), 81-94. doi: 10.1525/ahu.1997.22.1.81

Stoller: (2007). Ethnography/Memoir/Imagination/Story. Anthropology and humanism, 32(2), 178191. doi: 10.1525/ahu.2007.32.2.178

Strauss, S. (2000). Locating yoga: ethnography and transnational practice. En V. Amit (Ed.), Constructing the Field: Ethnographic Fieldwork in the Contemporary World: 162-194. Nueva York, Estados Unidos: Routledge.

Thurfjell, D. y Marsh, A. (Eds.) 2014. Romani pentecostalism: gypsies and charismatic Christianity. Frankfurt, Alemania: PL Academic Research.

Tilley-Lubbs, G. A. 2014. La Autoetnografía Crítica y el Self Vulnerable como Investigadora. REMIE: Multidisciplinary Journal of Educational Research, 4(3): 268-285.

Zapata, L. M. 2014. ¿Qué significa ser/no ser indio/a mapuche? «Pueblo indígena» y diseminación. En R. Guber (Ed.), Prácticas etongráficas: ejercicio de reflexividad de los antropólogos de campo: 183-224). Buenos Aires, Argentina: Miño y Dávila.

\section{3}

